\title{
Anti-Diabetic Activity of Lycopene Niosomes: Experimental Observation
}

\author{
Sharma $\mathrm{PK}^{* 1}$, Saxena $\mathrm{P}^{2}$, Jaswanth $\mathrm{A}^{3}$, Chalamaiah $\mathrm{M}^{1}$ and Balasubramaniam $\mathrm{A}^{2}$ \\ ${ }^{1}$ Food and Drug Toxicology Research Centre, National Institute of Nutrition (ICMR), Tarnaka, Hyderabad, India \\ ${ }^{2}$ Technocrats Institute of Technology-Pharmacy, Anand Nagar, BHEL, Bhopal, Madhya Pradesh, India \\ ${ }^{3}$ Procadence Institute of Pharmaceutical Sciences, Gajwel, Medak, Andhra Pradesh, India
}

*Corresponding author: Sharma PK, Food and Drug Toxicology Research Centre, National Institute of Nutrition (ICMR), Tarnaka, Hyderabad, India, Tel: +91 6626385275, E-mail: purnendusharma@gmail.com

Citation: Sharma PK, Saxena P, Jaswanth A, Chalamaiah M, Balasubramaniam A (2017) Anti-Diabetic Activity of Lycopene Niosomes: Experimental Observation. J Pharm Drug Devel 4(1): 103. doi: 10.15744/23489782.4.103

Received Date: July 22, 2017 Accepted Date: September 20, 2017 Published Date: September 22, 2017

\begin{abstract}
The lycopene is a known bioactive constituent of Lycopersicum esculentum and its application in diabetes is an active area of research. The lycopene has disadvantages such as susceptible to light, heat, and oxidants, which limit its therapeutic applications. In the present investigation, we reported lycopene niosomes formulation which can enhance its anti-diabetic application. The niosome formulation was prepared to preserve lycopene activity. The niosomes were characterized by entrapment efficiency, particle size, drug release profile, zeta potential and stability studies. The anti-diabetic activity of the formulation showed a significant reduction in blood glucose level compared to diabetic control on seventh and $14^{\text {th }}$ days $(\mathrm{p}<0.01$ and $\mathrm{p}<0.001$ respectively). The biochemical parameters such as total cholesterol, TGL, LDL, and VLDL were significantly decreased in treated groups when compared to control group. The overall results indicate that the lycopene-loaded niosomes are effective against diabetes. The niosome formulation is promising for wider applications which can play an important in the drug delivery and formulation research.
\end{abstract}

Keywords: Lycopene formulation; Niosomes; Oxidants; Anti-diabetic activity

\section{Introduction}

Lycopene is a principal carotenoid present in ripe tomatoes (Lycopersicum esculentum). It has characteristic red color and has gained focus for its potential health benefits $[1,2]$. The lycopene is a tetraterpene assembled from eight isoprene units, and it has eleven conjugated double bonds which give its deep red color and mostly responsible for its anti-oxidant activity. Several epidemiological and experimental studies provided the evidence that it may provide defense against many cardiovascular-related diseases and diabetes [3-5]. However, due to the presence of unsaturated bonds in its structure, it is susceptible to heat ( $\left.>80{ }^{\circ} \mathrm{C}\right)$, and light; and can be easily oxidized when exposed to these factors [6-8]. Therefore, there is necessary to protect lycopene from chemical damage before its application. Thus, to overcome these problems, niosome preparation has found to be promising and efficient.

Liposomes are associated with problems related to stability such as aggregation, fusion, leakage, and sedimentation on storage [9]. Niosomes are non-ionic surfactant based vesicles, having surfactant and cholesterol as excipients. Niosomes potentially have an advantage over these issues, which can enhance the rate and extent of solubilization into aqueous intestinal fluids. Similar to phospholipids, the use of nonionic surfactants imparts the ability to form vesicular systems (niosomes) when dispersed in aqueous media [10-16]. Niosomes can encapsulate both lipophilic and hydrophilic drugs, and protect them from external factors [17]. In many studies, it was found that niosomes behave like liposomes as they prolong the circulation of the drug, altering its body distribution and metabolic stability [15]. Niosomes has the ability to improve pharmacokinetic and pharmacodynamic profile owing to its higher affinity to the phospholipid, this not only improves its absorption but also enhances the duration of the activity. They offer many advantages over other vesicular delivery system such as higher stability, penetration enhancing properties and most importantly lower cost [18]. The high penetration and good drug loading potential make these niosomes a delivery system of choice for lycopene [19-25].

In the present investigation, we have formulated the lycopene niosomes. This study aimed to protect the anti-diabetic activity of lycopene in niosomes. The mechanism therein is to form a wall system to entrap the lycopene (core). For the wall system, span 60 was used as non-ionic surfactant and cholesterol which acts as membrane stabilizer to assist in solute retention by forming bilayer 
wall, and it also enhances the adhesion force between the wall and core materials. Hence, the niosome particles for lycopene were prepared, and its actual capabilities were studied by analyzing entrapment efficiency, release profile, stability, zeta potential. The in vivo antidiabetic activity of lycopene-loaded niosomes was evaluated for its efficiency.

\section{Materials and Methods}

\section{Material}

Lycopene extract in its pure form was isolated from Lycopersicum esculentum and characterized. Span 60, cholesterol, chloroform, n-hexane, ethanol, acetone was obtained from Merck Limited (Mumbai, India). Alloxan monohydrate was procured from SD Fine Chemicals Pvt. Limited (Biosar, India). Glibenclamide and Cisplatin were purchased from Sigma-Aldrich (India). All other chemicals were of analytical grade.

\section{Isolation of lycopene}

The lycopene was isolated from tomatoes (Lycopersicum esculentum), as described in the method by Sharma, et al. 2016. The resulting extract was stored in an amber color glass container with the inert environment at $4{ }^{\circ} \mathrm{C}$ for further processing. The extract was dried using rotary flash evaporator in inert environment of nitrogen gas by heating at $60{ }^{\circ} \mathrm{C}$ at $50 \mathrm{rpm}$ in dark condition [26].

\section{Preparation of lycopene formulation}

The lycopene niosomes were prepared by the method described by Sharma, et al. 2016. In this method, the pure extract was collected and dispersed in a small amount of solvent system (n-hexane: acetone: ethanol in 2:1:1 v/v). About $22 \mathrm{ml}$ of span 60 and cholesterol $(1: 1 \mathrm{~mol})$ were added to $10 \mathrm{ml}$ of above solvent system as organic phase having wall material. This phase was adsorbed over inert media with constant stirring at $60{ }^{\circ} \mathrm{C}$ temperature, as described by Sharma, et al. 2016. The aqueous phase (10 ml, mannitol solution: $\mathrm{pH}$ 7.4) was then slowly added to the lycopene-loaded inert media with vigorous shaking at $60^{\circ} \mathrm{C}$ temperature followed by sonication using an ultrasonic cell crusher (classic, sonicator, Lark Innovative Fine Teknowledge, Chennai, India) for 60 seconds/cycle in three cycles to protect the solution from heat buildup. Then it was kept for 2-3 hours for niosomes to stabilize. The suspension of self-assembled, lycopene-loaded niosomes was filtered using 0.45 -mm whatman filters (No-1) to remove inert material. The filtered suspension was then passed through column chromatography (Sephadex G-50 column) to separate un-entrapped lycopene. Finally, the niosome vesicles were collected and lyophilized (Lyodel, Delvac, India). The lyophilized formulation was stored in an air tight high-density plastic container [26].

\section{Characterization}

The pure lycopene extract was characterized, followed by lycopene niosomes characterization in terms of particle size, entrapment efficiency, zeta potential and in vitro drug release. Its biological activity was characterized by in vivo study in diabetic rats.

Characterization of lycopene: The characterization of lycopene was studied as described by Sharma, et al. 2016. They were characterized by physical appearance and microscopic characteristics, melting point (using Barnstead Mel-Temp Electrothermal Model 1001), solubility, determination of absorption maxima $\left(\lambda_{\max }\right)$ using UV spectrophotometer (Shimadzu 1700) and the absorption spectrum $\left(\lambda_{\max }\right)$ was obtained. The standard curve of the lycopene in $n$-hexane was prepared at the observed absorption maxima (O'Neil, 2006). The regressed calibration curve was plotted and observed for linearity and along with concentration range for beer lamberts law [26].

\section{Characterization of lycopene-loaded niosomes:}

Particle size analysis and zeta potential determination: Lycopene niosomes were spray dried on a clean glass slide (1x1 cm) and placed in a sample holder and fixed. Copper tape is used to mount sample to the stub. It was then gold coated. It was observed using JSM-6390 Scanning Electron Microscope (JEOL, USA) for evaluation of their morphology, particle size, and particle size distribution. Zeta potential of vesicles is determined by using zeta sizer (Malvern Instruments, UK). Niosomes suspension was diluted with distilled water and dropped into the zeta sizer electrophoretic cell. Each sample was measured six times at $25 \pm 0.1{ }^{\circ} \mathrm{C}$.

Entrapment efficiency (EE): The lycopene niosomes were loaded onto a Sephadex G50 column and was eluted with distilled water. The lycopene-loaded niosomes were eluted while free lycopene remained bound to the column. These separated vesicles were disrupted through the addition of $0.05 \mathrm{ml}$ TritonX-100 in $1 \mathrm{~mL}$ formulation in a centrifuge tube, and ultra-centrifuged at $120000 \mathrm{~g}$ for one h (Beckman L8-M, Beckman Coulter s.r.l., Milan Italy). The total lycopene-loaded in niosomes and the lycopene entrapped in niosomes were recovered and assayed by UV spectrophotometric method. The encapsulation efficiency was calculated using the following equation:

$$
E E \%=\frac{[\text { Encapsulated drug present after chromatography }]}{[\text { Total drug present before chromatography }]} \times 100
$$

Stability studies: Stability study of lycopene niosomes and the unloaded niosomes was carried out at $4{ }^{\circ} \mathrm{C}$ and $25{ }^{\circ} \mathrm{C}$, and in 
different $\mathrm{pH}$ conditions. Particle size, zeta potential and encapsulation efficiency were measured immediately after the preparation and on pre-determined time during the three-month storage [7,27].

In vitro drug release profile: The in vitro release of lycopene from niosomes was carried out using dialysis system. It consists of a dialysis bag and a receptor. The hydrated dialysis membrane $(15 \mathrm{kD})$ was tied to the funnel of diffusion cell assembly, and the setup was constituted. The niosomes $(3 \mathrm{ml}$ ) were packed in donor compartment (dialysis bag) closed by dialysis clip and placed in a beaker (receptor compartment) having $250 \mathrm{ml}$ phosphate buffer saline (PBS) (pH 7.4). The PBS was stirred at $50 \mathrm{rpm}$ ( $37 \pm 1$ ${ }^{\circ} \mathrm{C}$ ) using magnetic stirrer. The sampling was done by withdrawing $4 \mathrm{ml}$ of sample periodically till $72 \mathrm{~h}$ and replaced by fresh PBS of equal volume. The withdrawn samples were analyzed for drug content using UV spectrophotometer at $\lambda_{\max }(205 \mathrm{~nm})$. PBS was used as blank $[28,29]$.

\section{Anti-diabetic activity of lycopene-loaded nano-niosomes}

Animals: Wistar rats (150 g) of either sex, approximately 6-8-week-old were procured from Institute of Animal Health and Veterinary Biologicals, Indore, India. The animals were maintained in polypropylene cages with $12 \mathrm{~h}$ light and dark cycles at a temperature of $23 \pm 2{ }^{\circ} \mathrm{C}$ and a humidity of $55 \pm 5 \%$. They were maintained on laboratory diet and water ad libitum. The animals were acclimatized to laboratory condition for one week before the start of the experiment. The experiment was carried out following protocol approved by Institutional Animal Ethics Committee (TIT/IAEC/831/PHARMACEUTICS/2012/07) at TIT-Pharmacy, Bhopal, India.

Preparation of diabetic rats: The hyperglycemia was induced by intraperitoneal injection of a freshly prepared aqueous solution of alloxan monohydrate (SD Fine Chemicals Pvt. Ltd., Biosar) (150 mg/kg), to overnight fasted rats. The normal control rats received a similar volume of vehicle, normal saline ( $2 \mathrm{ml} / \mathrm{kg}$ body weight) along with diet. Animals that did not develop hyperglycemia after $48 \mathrm{~h}$ of alloxan injection were rejected, and new animals were used. Immediately after confirmation of diabetes, rats were classified into six groups of six rats each [30].

Experimental design for anti-diabetic activity: This study involves six groups of rats which comprise of two control groups (normal and diabetic controls) and four test groups; each group had six rats and housed three animals in each cage, for proper identification. Group I-normal control: The animals in this group were given normal saline orally, and they were fed with regular rat chow and water ad libitum. Group II-diabetic control: The animals were injected intraperitoneally with alloxan monohydrate $150 \mathrm{mg} / \mathrm{kg}$ to induce diabetes mellitus. Also, the animals were fed with regular rat chow and water ad libitum. Group III \& IV were treated with lycopene niosomes by oral administration (100 \& $200 \mathrm{mg} / \mathrm{kg}$ respectively) along with normal rat chow and water ad libitum. Group V was treated with Glibenclamide $(5 \mathrm{mg} / \mathrm{kg})$ with normal rat chow and water ad libitum, and Group VI received pure lycopene extract $(200 \mathrm{mg} / \mathrm{kg})$ orally and served as reference standard. The treatment continued for 14 consecutive days. The blood samples were collected from the tail vein of the animals, and the fasting blood glucose level was estimated on $0,7^{\text {th }}$ and $14^{\text {th }}$ day of dosing period [31].

Biochemical analysis: The blood was withdrawn on the 15th day directly from the heart through cardiac puncture method; the blood was collected in vacutainer tubes. The collected blood sample was centrifuged at 3500 rpm for 20 minutes, and serum glucose levels were determined using the glucose oxidase-peroxidase method (Coral Clinical Systems, Goa, India) [32]. The biochemical parameters such as serum triglyceride (ST), serum cholesterol (SC) and high-density lipoprotein (HDL), very lowdensity lipoprotein (VLDL) and low-density lipoprotein, (LDL) were determined [33].

\section{Statistical analysis}

The results are expressed as Mean \pm Standard error (S.E). All the statistical analysis was performed with Graph Pad Instat Software (Version 3.0, Graph Pad Software, California, USA) using one-way analysis of variance (ANOVA) followed by Dunnett's ' $t$ ' test for multiple comparisons and student's t-test for a single comparison. Significance was expressed as ${ }^{\star} \mathrm{p}<0.01 ;{ }^{\star *} \mathrm{p}<0.001[34-36]$.

\section{Results}

\section{Isolation of lycopene}

The isolated lycopene extract appeared as odorless brick red crystals as reported by Sharma, et al., 2016. The microscopy revealed the appearance of lycopene as long deep red needles. The melting point range was confirmed as $172-173{ }^{\circ} \mathrm{C}$ which complies with pure lycopene. The solubility of lycopene was done to confirm its solubility; the solubility was studied with various solvents, and it complies with literature $[7,37,38]$. The purity of lycopene was determined with UV spectrophotometric method using absorption spectra $\left(\lambda_{\max }\right)$; the $\lambda_{\max }$ was obtained at $504 \mathrm{~nm}$ which is comparable with the reference spectrum of the lycopene [1]. The initial characterization was revealed the presence of pure lycopene in the extract.

\section{Formulation development and characterization of niosomes}

The isolated lycopene extract was formulated in niosomes and this lycopene niosomes formulation was characterized.

Physical characterization (Particle size, size distribution and zeta potential): The particle size and size distribution of lycopene 
niosomes were ranged from 175 to $235 \mathrm{~nm}$ with average hydrodynamic particle size $202 \pm 41 \mathrm{~nm}$ which is similar to results reported by Sharma, et al., 2016, owing to same methodology of preparation. Morphology of niosomes was studied and confirmed using scanning electron microscopy (SEM) which was found to be in accordance with hydrodynamic particle size. The particles were spherical and morphologically similar. The zeta potential was studied at different $\mathrm{pH}$ conditions $(4,5.6$ and 9$)$, zeta potential value was found to be stable at $-2.25 \pm 0.2 \mathrm{mV}$ and the changes in zeta potential over stability period was not significant, indicating the absence of ionization of the membrane components [14,16,18,39].

Entrapment efficiency (EE): The lycopene niosomes were evaluated for entrapment efficiency and revealed the mean EE was $62.8 \pm 2 \%(n=3)$.

Stability studies: The stability of both empty and lycopene niosomes, were monitored in terms of vesicle size, EE, and zeta potential during three-month storage at 4 and $25^{\circ} \mathrm{C}$. The zeta potential of empty niosomes did not change in an important way at different $\mathrm{pH}$ conditions and during storage conditions.

Drug release profile: The drug release profile of lycopene niosomes was observed, and linear regression analysis of lycopene release data supports the diffusion controlled mechanism of its release. It was found that initially lycopene release was at higher rate which can be contributed to the membrane-bound lycopene, followed by encapsulated lycopene from the formulation. During first $24 \mathrm{~h}$, the initial lycopene release was found to be about $19 \%$ and during the next $48 \mathrm{~h}$, it was $48.3 \%$ of the total lycopene from niosomes. The mathematical models revealed and supported the mechanism of lycopene release from niosomes (Zeroorder kinetics, First-order kinetics, Higuchi kinetics, Korsmeyer-Peppas and Hixson-Crowel models). The sustained release of membrane bound lycopene and followed encapsulated lycopene supports the prolonged release function of the niosomes. Higuchi kinetics, Korsmeyer-Peppas and Hixson-Crowel models supported the mechanism of lycopene release. This implies that lycopene in the present formulation has a sustained and prolong release profile, which is required to maintains an optimum concentration for its in vivo activity, which is very important for different herbal and natural product applications.

\section{Anti-diabetic activity}

The oral administration of the formulation in the doses 1000 to $5000 \mathrm{mg} / \mathrm{kg}$ did not produce significant changes in behavior or toxicity in the rats indicating that the formulation is not toxic under the observable conditions (OECD revised draft 420). Administration of lycopene nano-niosome formulation (100 \& 200mg/kg) for 14 days has reduced the blood glucose level of diabetes induced animals as compared to diabetic control group. There was a significant decrease in the blood glucose level on the $7^{\text {th }}(\mathrm{p}<0.01)$ and $14^{\text {th }}(\mathrm{p}<0.001)$ day of the diabetes induction, indicating the anti-diabetic effect of the lycopene niosome formulation (Table 1). The lycopene niosomes $(100 \mathrm{mg} / \mathrm{kg}$ ) were able to reduce the blood glucose level to 0.6 times compared to diabetics control after 7 days and 0.4 times after 14 days. Whereas, lycopene niosomes $(200 \mathrm{mg} / \mathrm{kg})$ reduced the blood glucose level to 0.4 and 0.35 times related to control after 7 days and 14 days respectively. The efficacy of lycopene niosomes were found were similar to pure lycopene extract as well as Glibenclamide (positive control), but lycopene niosomes $(200 \mathrm{mg} / \mathrm{ml}$ ) were more effective than pure lycopene extract. The niosomes were able to produces time dependent control over blood glucose level over 14 days. The control release profile will further enhance the effectiveness of the formulation for prolong period. This might me due to diffusion control lycopene delivery as supported by in vitro kinetics.

\begin{tabular}{|c|c|c|c|c|}
\hline \multirow{3}{*}{ Groups } & \multirow{3}{*}{$\begin{array}{c}\text { Dose } \\
(\mathrm{mg} / \mathrm{kg})\end{array}$} & \multicolumn{3}{|c|}{ Blood glucose level (mg/dl) } \\
\hline & & \multicolumn{3}{|c|}{ Treatment (Days) } \\
\hline & & 0 & 7 & 14 \\
\hline $\begin{array}{c}\text { Control } \\
\text { (Normal Saline) }\end{array}$ & $\begin{array}{l}\text { 2, p.o. } \\
\text { (ml/kg) }\end{array}$ & $90.3 \pm 4.6$ & $90.8 \pm 3.6$ & $90.8 \pm 6.6$ \\
\hline $\begin{array}{l}\text { Alloxan induced } \\
\text { Diabetic control }\end{array}$ & 150, i.p. & $263.3 \pm 18.4$ & $262 \pm 19.2$ & $260.3 \pm 17.7$ \\
\hline Lycopene niosome & 100, p.o. & $261 \pm 10.3$ & $152.3 \pm 10.2^{*}$ & $110.8 \pm 3.8^{\star *}$ \\
\hline Lycopene niosome & 200, p.o. & $269 \pm 13.3$ & $109.6 \pm 11.2^{*}$ & $91.6 \pm 4.3^{* *}$ \\
\hline Glibenclamide & 5, p.o. & $260 \pm 14.3$ & $110 \pm 9.2^{*}$ & $90.8 \pm 6.2^{\star *}$ \\
\hline $\begin{array}{l}\text { Lycopene } \\
\text { extract }\end{array}$ & 200, p.o. & $265 \pm 6.8$ & $136.5 \pm 7.8^{*}$ & $100.5 \pm 1.61^{\star *}$ \\
\hline $\begin{array}{l}\text { Values } \\
{ }^{*} \mathrm{p}<0.01 \\
{ }^{* *} \mathrm{p}<0.0 \\
\text { Table } 1\end{array}$ & $\begin{array}{l}\text { expressed } \\
\text { s. Control } \\
\text { Vs. Contr } \\
\text { ffect of for }\end{array}$ & ation on allo & induced diabe & \\
\hline
\end{tabular}

The lycopene niosomes also produced a significant decrease in the biochemical parameters viz., total cholesterol, TGL, LDL and VLDL when compared to diabetic control animals and increased the HDL levels indicating the protective effect of the lycopene formulation on diabetes-related complications, as given in Table 2. The TGL level for $200 \mathrm{mg} / \mathrm{ml}$ dose lycopene formulation were significantly less than diabetic control as well as pure lycopene extract, whereas the $100 \mathrm{mg} / \mathrm{ml}$ did not produce any significant decrease, which might be due to low dose of lycopene and high metabolism over 14 days. The HDL levels were significantly 
reduced as compared to diabetic controls. The efficiency of lycopene niosomes (at both 100 and $200 \mathrm{mg} / \mathrm{ml}$ dose) in lowering LDL levels were significantly high as compared to diabetic control and pure lycopene extract, whereas there was no much difference in VLDL levels. The total cholesterol was also significantly reduced by lycopene niosomes as well as pure lycopene as compared to diabetic control but effectiveness of lycopene niosomes were more pronounced than pure extract.

\begin{tabular}{|c|c|c|c|c|c|}
\hline Treatment & $\begin{array}{c}\text { TGL mg/ } \\
\mathbf{d l}\end{array}$ & $\begin{array}{c}\text { HDL } \\
\mathbf{m g} / \mathbf{d l}\end{array}$ & $\begin{array}{c}\text { LDL } \\
\mathbf{m g} / \mathbf{d l}\end{array}$ & $\begin{array}{c}\text { VLDL } \\
\mathbf{m g} / \mathbf{d l}\end{array}$ & $\begin{array}{c}\text { Total Choles- } \\
\text { terol }\end{array}$ \\
\hline $\begin{array}{c}\text { Control } \\
\text { (Normal Saline) }\end{array}$ & $77.8 \pm 5.1$ & $24.5 \pm 1.3$ & $39.1 \pm 4.1$ & $15.5 \pm 0.82$ & $79.1 \pm 5.1$ \\
\hline $\begin{array}{c}\text { Alloxan induced } \\
\text { Diabetic control }\end{array}$ & $116.2 \pm 7.3$ & $73.7 \pm 5.2$ & $145.4 \pm 9.3$ & $23.2 \pm 0.96$ & $242.4 \pm 7.3$ \\
\hline $\begin{array}{c}\text { Formulation } \\
(100 \mathrm{mg} / \mathrm{kg})\end{array}$ & $102.7 \pm 6.8$ & $35.7 \pm 2.9^{*}$ & $69.9 \pm 4.0^{* *}$ & $20.5 \pm 1.3$ & $126.2 \pm 8.3$ \\
\hline $\begin{array}{c}\text { Formulation } \\
(200 \mathrm{mg} / \mathrm{kg})\end{array}$ & $90.5 \pm 7.9^{*}$ & $39.3 \pm 2.5^{*}$ & $51.1 \pm 2.2^{* *}$ & $18.1 \pm 0.57$ & $108.5 \pm 7.6$ \\
\hline $\begin{array}{c}\text { Glibenclamide } \\
(5 \mathrm{mg} / \mathrm{kg})\end{array}$ & $83.7 \pm 4.9^{*}$ & $34.4 \pm 2.8^{*}$ & $39.8 \pm 1.2^{* *}$ & $16.7 \pm 0.97$ & $90.9 \pm 4.9$ \\
\hline $\begin{array}{c}\text { Lycopene extract } \\
(200 \mathrm{mg} / \mathrm{kg})\end{array}$ & $123.6 \pm 2.8$ & $29 \pm 1.1^{*}$ & $106.9 \pm 0.77$ & $30.7 \pm 2.1$ & $161.4 \pm 2.1$ \\
\hline
\end{tabular}

Values are expressed as Mean $\pm S E,(n=6)$ by student's t-test

${ }^{*} \mathrm{p}<0.01 \mathrm{Vs}$. Control

${ }^{* *} \mathrm{p}<0.001 \mathrm{Vs}$. Control

Table 2: Effect of formulation on biochemical parameters in alloxan induced diabetes

\section{Discussion}

The niosomes are well-established vehicles for better pharmacokinetic and pharmacodynamic profile than other conventional formulation of natural extracts due to its higher affinity to the phospholipids. This improves the absorption of the active drug and molecules, and increases the duration of the activity as it slowly releases the active principle. The niosomes formulation is stable and has sustained releases profile which makes it a carrier of choice.

The isolated lycopene was formulated in niosomes as the lycopene degradation is caused during processing or formulation by isomerization and oxidation, due to the influence of factors like heat, light, and oxygen, against which it can act as a potential system. The niosome are processed under less stressful conditions and is suitable for lycopene as it can be process below degradation conditions. It can provide high resistance to oxidative stress induced by different sources of free radicals [26,40].

The lycopene niosomes prepared were successful and found to be in uniform size having high entrapment efficiency (EE), which can be attributed to the maximum surface area for contact achieved during development between wall material and lycopene. The span 60 for wall system was the best choice due to its potential properties of emulsification, water-solubility, film-formation, edibility and biodegradable property. It also helps in providing the maximum EE, due to its alkyl chain length and phase transition temperature. Also, cholesterol acted as membrane stabilizer to assist solute retention by forming the bilayer, thus providing higher entrapment efficiency and stability as well as it improves the adhesion force between the wall and core materials [26]. The mannitol solution ( $\mathrm{pH}$ 7.4) was used as an aqueous phase to impart isotonicity to the niosomes. In niosome's structure, the lycopene was predicted to be embedded in the bilayer of surfactant and cholesterol through a hydrogen bond, thus was found to be protected against oxidative stress. The wall system of long chain surfactant and cholesterol help in protection against light. The absence of agglomeration and instability was observed in the niosomes formulation. The entrapment efficiency of the niosomes was $62.8 \pm 2 \%(n=3)$, and the average particle size of the niosomes was $202 \mathrm{~nm}$ with a uniform, spherical unilamellar outer structure. The particle size of lycopene niosomes was supportive in circumventing the bio-environment and avoids the uptake by rough endoplasmic reticulum. The zeta potential of empty niosomes has not shown any significant change at a different range of $\mathrm{pH}$ from 4 to 9, indicating the absence of ionization phenomena of the membrane components. Both empty and lycopene niosomes confirmed good stability over a three-month storage period. In fact, there was no statistically significant difference in size, zeta potential and entrapment efficiency of the niosomes $(\mathrm{P}>0.05)$ after three-months storage at ambient temperature. Moreover, the loss of entrapment efficiency of niosome formulation was not significant during stability studies. The in vitro lycopene release was gradual with time. During initial release phase of lycopene, it was faster over a period of 10 hours. This was perhaps due to the incorporation of lycopene in the outer wall of niosomes. The lycopene release after that was found to be steady, and $67.3 \%$ of the entrapped lycopene was traced during $72 \mathrm{~h}$. The lycopene release mechanism from niosomes formulation was determined using mathematical kinetic models: Zero-order kinetics, First-order kinetics, Higuchi kinetics, Korsmeyer-Peppas and Hixson-Crowel models [26]. The mechanism of drug release was found to be the Fickian type and initially obeyed zero-order release kinetics for initial $10 \mathrm{~h}$, after that the regression equation was the best fit in Korsmeyer-Peppas model $\left(\mathrm{r}^{2}=0.9915\right)$. Thus, the in vitro lycopene release from niosomes was sustained, and prolonged profile required for effective treatment, which might be due to maximum lycopene entrapment efficiency and uniform sized particles prepared innovatively. 
The antidiabetic study showed the marked decrease in blood glucose level as well as various biochemical parameters in diabeticinduced rats when treated with lycopene formulation of doses $(100 \& 200 \mathrm{mg} / \mathrm{kg})$ for 14 days as compared to antidiabetic drug glibenclamide $(5 \mathrm{mg} / \mathrm{kg})$. The level of blood glucose in lycopene treated group $(91.6 \pm 4.3 \mathrm{mg} / \mathrm{dl})$ reached almost equal to glibenclamide treated group $(90.8 \pm 6.2 \mathrm{mg} / \mathrm{dl})$ after 14 days of treatment. Thus, provide evidence that the lycopene at a dose of $200 \mathrm{mg} / \mathrm{kg}$ is having antidiabetic activity similar to glibenclamide $(5 \mathrm{mg} / \mathrm{kg})$. The observed activity might be due to the preservation of potent activity of lycopene, which attenuates $\mathrm{T}$ cell-dependent adaptive immune response, probably by increasing total antioxidant capacity of the serum and also due to its effect on glucose metabolism and possibly insulin secretion. Lycopene is a powerful antioxidant with a singlet oxygen quenching capacity greater than that of $\beta$-carotene and vitamin E by 47 and 100 times, respectively [39,41]. This lycopene formulation also has a potent hypo-cholesterolemic activity as shown in results [42]. These results show the superiority of the method used for the preparation of lycopene niosome formulation in its stability, drug release and more importantly in preserving its in vivo and in vitro activity.

\section{Conclusion}

The lycopene niosome was found to be efficient and has well-preserved the lycopene's activity. The niosomes promises to be a potential technique for natural product development. The niosomes have potential in efficient delivery of a broad spectrum of anti-diabetic natural products and agents. The formulation is simple and reproducible for further applications, and could be useful for different applications.

\section{Acknowledgement}

We would like to acknowledge management and staff of all the affiliated department of institutions of authors for their support during the study.

\section{References}

1. Shi J, Mazza G, Le Maguer M (2002) Lycopene from Tomatoes In: Functional Foods: Biochemical and Processing Aspects, Vol 2. CRC Press, Boca Raton, USA.

2. Rao AV, Rao LG (2004) Lycopene and Human Health. Curr Top Nutr Res 2: 127-36.

3. Clinton SK (1998) Lycopene: chemistry, biology, and implications for human health and disease. Nutr Rev 56: 35-51.

4. Giovannucci E, Rimm EB, Liu Y, Stampfer MJ, Willett WC (2002) A prospective study of tomato products, lycopene, and prostate cancer risk. J Natl Cancer Inst 94: 391-8.

5. Omoni AO, Aluko RE (2005) The anti-carcinogenic and anti-atherogenic effects of lycopene: a review. Trends Food Sci Technol 16: 344-50.

6. Bhattacharya S (2009) Phytosomes: Emerging Strategy in Delivery of Herbal Drugs and Nutraceuticals. Pharma Times 41: 9-12.

7. Lee MT, Chen BH (2002) Stability of lycopene during heating and illumination in a model system. Food Chem 78: 425-32.

8. Pesek CA, Warthesen JJ (1987) Photodegradation of carotenoids in vegetable juice system. J Food Sci 52: 744-6.

9. Uchegbu IF, Vyasb SP (1998) Non-ionic surfactant based vesicles (niosomes) in drug delivery. Int J Pharm 172: 33-70.

10. Baroli B, Delogu G, Fadda AM, Podda G, Sinico C (1999) Vesicle formation from hexa substituted cyclophosphazenic derivatives. Int J Pharm 183: 101-7.

11. Kushwaha A, Murthy RN, Murthy SN, Elkeeb R, Hui X, et al. (2015) Emerging therapies for the treatment of ungual onychomycosis. Drug Dev Ind Pharm 41: 1575-81.

12. Manda P, Kushwaha AS, Kundu S, Shivakumar HN, Jo SB, et al. (2016) Delivery of ziconotide to cerebrospinal fluid via intranasal pathway for the treatment of chronic pain. J Control Release 224: 69-76.

13. Williams M (2006) The Merck Index: an Encyclopedia of Chemicals, Drugs, and Biologicals (14 $4^{\text {th }}$ edn). Merck Research Laboratories, White house Station, New Jersey.

14. Rath S, Olempska-Beer Z (2009) Lycopene Extract from Tomato: Chemical and Technical Assessment (CTA). Lycored Natural Products Industries Ltd, Israel. 15. Rogerson A, Cummings J, Willmott N, Florence AT (1988) The distribution of doxorubicin in mice following administration in niosomes. J Pharm Pharmacol 40: $337-42$.

16. Sathivel M, Kannan K, Manavalan R, Senthamarai R (2012) Formulation and in vitro evaluation of niosomes containing oxcarbazepine. Internat J Pharm Pharmaceutical Sci 4: 563-7.

17. Yoshida H, Lehr CM, Kok W, Junginger HE, Verhoef JC, et al. (1992) Niosomes for oral delivery of peptide drugs. J Control Release 21: 145-53.

18. Manconi M, Sinico C, Valenti D, Loy G, Fadda AM (2002) Niosomes as carriers for tretinoin. I. Preparation and properties. Int J Pharm 234: $237-48$.

19. Hu C, Rhodes DG (1999) Proniosomes: a novel drug carrier preparation. Int J Pharm 185: 23-35.

20. Adelli GR, Balguri SP, Majumdar S (2015) Effect of Cyclodextrins on Morphology and Barrier Characteristics of Isolated Rabbit Corneas. AAPS PharmSciTech 16: 1220-6.

21. Balguri SP, Adelli G, Bhagav P, Repka MA, Majumdar S (2015) Development of nano structured lipid carriers of ciprofloxacin for ocular delivery: Characterization, in vivo distribution and effect of PEGylation. Invest Ophthalmol Vis Sci 56: 2269.

22. Banker GS, Rhodes CT (2002) Pharmacokinetics In: Modern Pharmaceutics ( $4^{\text {th }}$ edn) Marcel Dekker, New York, USA.

23. Lavechia R, Zuorro A (2008) Enhancement of Lycopene Extraction from Tomato Peels by Enzymatic Treatment. Chem Eng Trans 14: 301-8.

24. Mosmann T (1983) Rapid colorimetric assay for cellular growth and survival: application to proliferation and cytotoxicity assays. J Immunol Methods 65: 55-63.

25. Nahum A, Hirsch K, Danilenko M, Watts CK, Prall OW, et al. (2001) Lycopene inhibition of cell cycle progression in breast and endometrial cancer cells is associated with reduction in cyclin D levels and retention of p27(Kip1) in the cyclin E-cdk2 complexes. Oncogene 20: 3428-36.

26. Sharma PK, Saxena P, Jaswanth A, Chalamaiah M, Tekade KR, et al. (2016) Novel Encapsulation of Lycopene in Niosomes and Assessment of its Anticancer Activity. J Bioequiv Availab 8: 224-32. 
27. Kushwaha A, Jacob M, Shiva Kumar HN, Hiremath S, Aradhya S, et al. (2015) Trans-ungual delivery of itraconazole hydrochloride by iontophoresis. Drug Dev Ind Pharm 41: 1089-94.

28. Zange R, Li Y, Kissel T (1998) Biocompatibility testing of ABA triblock copolymers consisting of poly(L-lactic-co-glycolic acid) A blocks attached to a central poly(ethylene oxide) B block under in vitro conditions using different L929 mouse fibroblasts cell culture models. J Control Release 56: 249 -58.

29. Kushwaha AS, Repka MA, Narasimha Murthy S (2017) A Novel Apremilast Nail Lacquer Formulation for the Treatment of Nail Psoriasis. AAPS PharmSciTech. 30. Bailey CC, Bailey OT (1943) The Production of Diabetes Mellitus in Rabbits with Alloxan. J Amer Med Ass 21: 1165-6.

31. Neeli GS, Girase GS, Kute SH, Karki SS, Shaikh MI (2007) Antidiabetic activity of herb of Cynodon dactylon Linn. Pers. in alloxan induced diabetic rats and in euglycemic rats. Indian Drugs (Drug Manufact) 44: 602-5.

32. Sushruta K, Satyanarayana S, Srinivas N, Sekhar JR (2006) Evaluation of the Blood-Glucose Reducing Effects of Aqueous Extracts of the Selected Umbelliferous Fruits Used in Culinary Practices. Tropical J Pharmaceut Res 5: 613-7.

33. Kale SR, Kale RR (2007) Practical biochemistry and clinical pathology (17 ${ }^{\text {th }}$ edn). Nirali prakashan, Pune, India.

34. Kushwaha A, Shivakumar HN, Murthy SN (2016) Iontophoresis for drug delivery into the nail apparatus: exploring hyponychium as the site of delivery. Drug Dev Ind Pharm 42: 1678-82.

35. Balguri SP, Adelli GR, Majumdar S (2016) Topical ophthalmic lipid nanoparticle formulations (SLN, NLC) of indomethacin for delivery to the posterior segment ocular tissues. Eur J Pharm Biopharm 109: 224-35.

36. Kushwaha AS, Sharma P, Shivakumar HN, Rappleye C, Zukiwski A, et al. (2017) Trans-ungual Delivery of AR-12, a Novel Antifungal Drug. AAPS PharmSciTech.

37. Viuda-Martos M, Sanchez-Zapata E, Sayas-Barberá E, Sendra E, Pérez-Álvarez JA, et al. (2014) Tomato and tomato byproducts. Human health benefits of lycopene and its application to meat products: a review. Crit Rev Food Sci Nutr 54: 1032-49.

38. Mashal M, Attia N, Puras G, Martínez-Navarrete G, Fernández E, et al. (2017) Retinal gene delivery enhancement by lycopene incorporation into cationic niosomes based on DOTMA and polysorbate 60. J Control Release 254: 55-64.

39. Liu CC, Huang CC, Lin WT, Hsieh CC, Huang SY, et al. (2005) lycopene supplementation attenuated xanthine oxidase and mycloperoxidase activities in skeletal muscle tissues of rats after exhaustive exercise. Br J Nutr 94: 595-601.

40. Salama MF, Seliem EI, Mahmoud KF, Amin AA (2015) Physiochemical Characterization and Oxidative Stability of Encapsulated Nano Lycopene Pigments Extracted By $\mathrm{CO}_{2}$ Fluid Extraction. Int J Curr Microbiol App Sci 4: 307-20.

41. Di Mascio P, Kaiser S, Sies H (1989) Lycopene as the most efficient biological carotenoid singlet oxygen quencher. Arch Biochem Biophys 274 : 532-8.

42. Fuhrman B, Elis A, Aviram M (1997) Hypocholesterolemic effect of lycopene and beta-carotene is related to suppression of cholesterol synthesis and augmentation of LDL receptor activity in macrophages. Biochem Biophys Res Commun 233: 658-62.

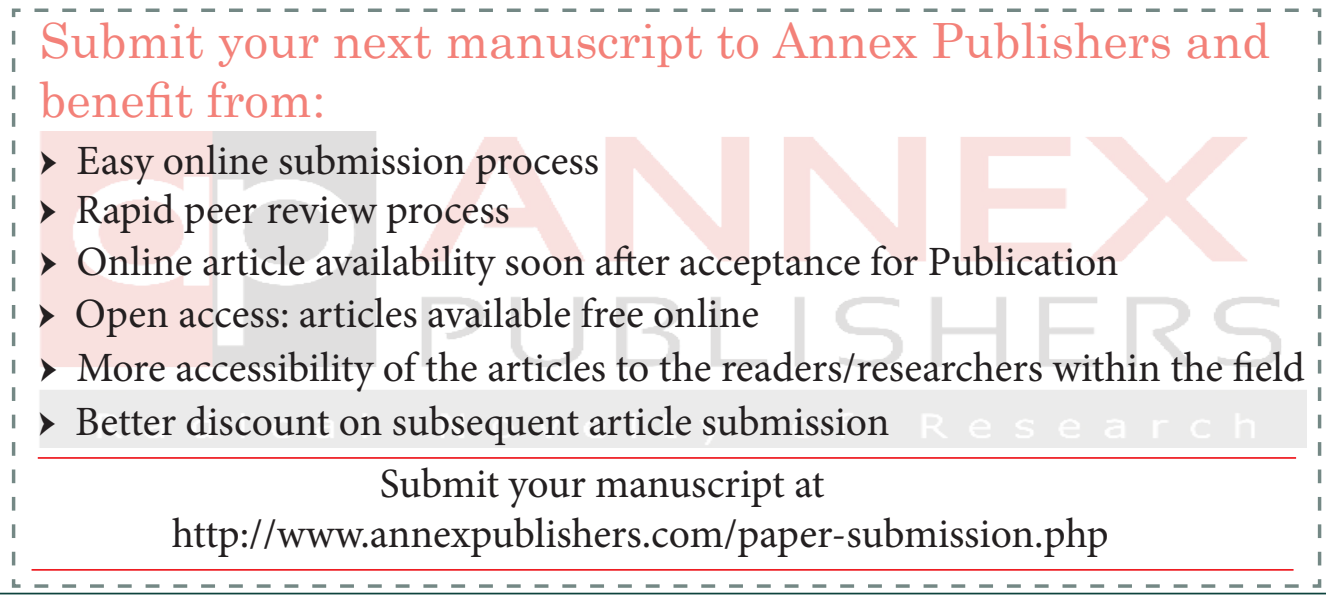


